\title{
Sustainability through Service Marketing- Below the Line Bangladesh
}

\author{
Mahreen Mamoon ${ }^{1}$, Hamidul Islam ${ }^{2}$ \\ ${ }^{1,2}$ (Lecturer, Marketing, American International University-Bangladesh, Bangladesh)
}

\begin{abstract}
Social Marketing is a zero-sum game as it begets a dilemma to the marketer in terms of risk, benefit and cost. The descriptive paper covers the social Marketing concept from the facet of a Bangladeshi Company $S M C$, and its possible contribution to the below the line consumers. Attempt has been made to highlight various marketing programs and communication tools to cover the unidentified segments and ways to isolate them to better focus the strategic goals.
\end{abstract}

Keywords - Sustainability, Social marketing, Promotion, Positioning

\section{INTRODUCTION}

Bangladesh has embarked on major strategies to advance its social marketing approaches. Their main focus is to facilitate sustainable consumption through social marketing. Notably, social marketing involves the use of various techniques and concepts with the aim of changing a specified behavioral change for the benefit of the society. In addition, it aims at promoting the society's well being. Therefore, only products and services that are of benefit to the society are promoted while at the same helping the public to avoid harmful products.

Social Marketing Company (SMC) is a marketing organization in Bangladesh that plays a great role in maintaining a productive social marketing. It has greatly contributed in reproduction and provision of child health services in the country (Weinreich, 2010). SMC has started various social marketing programs. Some of these programs include the following: family planning, prevention of diseases, and child health among others. Their main aim is to promote quality of life of the less privileged population in the country. The company which is privately managed works closely with the national and international governments as well as donors. Its sustainable efforts on social marketing have benefited its population significantly.

In this case, various commercial management techniques are usually applied in order to market, popularize, buy and sell product and services that are of benefit to the people. They also advocate for fair prices of goods and services which people can afford. Indeed, social marketing in Bangladesh focus on high availability and affordability of the product and services to the common public. Social marketing in Bangladesh uses two major strategies in order to achieve their objects. They include: multi-strategy communication as well as sustainability to enhance changed behavior among the members of the society (Weinreich, 2010). The communication is aimed at facilitating adoption and initiation of a positive behavior change. Virtually, commercial marketing technique is mainly used to support the change of behaviors on the use of products.

The model of social marketing used in Bangladesh has achieved remarkable success. For this reason, it has become a best practice not only in Bangladesh but also in the international scenes. This has made United States together with other Asian countries to include the social marketing program in their curriculum. SMC has made major contributions in the national program. In the health sector, some of the major contribution has been seen in the social marketing of family planning through the use of contraceptives. This has played a great role in meeting the objective of the Bangladesh government on population control.

Social marketing has greatly been achieved through the use of an innovative communication that facilitates behavior change. The company is able to offer large scale dissemination of information regarding the use of contraceptives. Moreover, it takes a major role in advertising these products to the larger population. Some of the barriers that have faced SMC in its endeavor of social marketing included: the larger illiterate members of the Bangladesh society, majority of the population was poor therefore access to media or buying the contraceptives was received with skepticism. In order to deal with this situation, SMC has to embark on strong and innovative sense of communication to facilitate behavior change. The major approach was on family planning and the use of contraceptives. The innovative modes of communication led to the success of these programs. This has made this company to gain a worldwide recognition. Its success is also based on its effort to promote health messages as well as enhance the sale and buying of the branded products only. Their advertisement and promotion is carried out not only through media but also through any means that will make the target audience receive the intended message. Thus, messages are found on billboards, buildings, shops, banners, water tanks among others. 
SMC uses a hallmark, Mobile Film Program (MFP) which has acted as a major factor in its global recognition. The company is able to broadcast shows that reach a large audience especially in rural areas. The shows focus on health communication as well as promotion of branded products. This enables people to learn new information hence become more informed to make the right choices regarding family planning and the use of products (National Strategy for Anemia Prevention and Control in Bangladesh, 2007). The statistics shows that about 63 percent of the viewers are able to change their behavior from the new information gained from these shows. They use professionals such as pharmacists and medical practitioners to reach the rural areas. They also offer training to health providers in order to enhance their knowledge and skills to meet the needs of the population.

Some of the strategies used by the social marketing approach include the following: market segmentation, development of brands as well as effective placement of their products. Due to its ability to reach large number of people, the company has developed in a way that it is able to provide condoms and pills to specified markets. These are areas that are effectively supported by the advertising and promotion mechanisms (Harvey, 1999). As a result, this has raised the awareness and loyalty of the brands for certain segments of the population. SMC is able to sell its products such as contraceptives by positioning them at strategic points in the market areas. Some major types of condoms are the Raja and Hero which are affordable for low income individuals. While the U \& ME and Minicon are meant for upper income population. Therefore, they are able to provide their products to certain specific population helping to meet their needs as well as maintain their status.

The company also takes care of the welfare of the children by providing micro nutrition programs in the country. These products are branded and easily available for home based food fortification. This helps to address the issue of Iron deficiency that leads to Anemia. Parents and care givers are made aware of the importance of using fortified food for the benefit of the child. This limits cases of ignorance that is rife among parents (Gerard, 2007). SMC has a factory that manufactures branded products such as ORS that is meant to ensure the safety of products. There has been increased demand of ORS. As a result, the company has established more facilities that ensure that products are readily available. The company is able to manufacturer large quantities of these products helping to reverse the issue of deficiency. SMC is embarking on a mechanism that will ensure that it is in a position to achieve their national health objectives (Harvey, 1999). This is through the expansion of their services provision as well as the products that it is able to sell annually. Their main commitment is to ensure that the less privileged population is served in terms of provision of products that are available as well as affordable.

Bangladesh has been able to go to great heights due to availability of social media that ensures that information is able to reach people in remote areas. It has also been able to establish online users who widen the reach of this company. For this reason, they have been working on social media websites that are aimed at maintaining sustainability of their clients (Harvey, 1999). This SMC will be able to grab a big chance in the field of adverting and marketing of their education to the public. Consecutively, they will be able to increase their international trends with their consumers.

Sustainable consumption has been the major areas of focus on social marketing. Sustainable consumption is important taking into consideration that majority of population in Bangladesh and most parts of Asia live in poverty. For this reason, they have increased the need for production and consumption of basic commodities and services (Weinreich, 2010). Most companies have ignored this understanding placing much emphasis on production of goods that are relatively expansive for middle-income earners. As a result, majority cannot afford essential commodities making it hard for them to effectively buy contraceptives and hence not possible to exercise family planning.

By taking care of their population, SMC has paved an avenue for increased growth of economy as well as increased international markets that are willing to invest into the country. Population growth has been controlled due to campaign on family planning and healthy living. This has also increased life spans for the majority in Bangladesh (National Strategy for Anemia Prevention and Control in Bangladesh, 2007). People are also moving from middle to high income earners increasing the rate of consumption of their products. Social marketing in Bangladesh has been able to improve the well-being of their people diverting majority's view on material commodities and the focus on profit making. In this case, sustainable consumption has been understood as situation where the needs and demands of consumers are fulfilled efficiently by the major players in social marketing (Harvey, 1999). This has helped to minimize negative effects on environmental, social as well as economical effects. Ultimately, more people are involved in meaningful work, community engagement as well as improved health.

\section{CONCLUSION}

SMC has played a great role in encouraging behavior modification among the population. The success of SMC in Bangladesh has been attributed to its ability to spread health messages to their target population. They have been able to understand their audience in terms of their social needs. This is through provision of social and economic needs. They have enhanced provision of branded products that aims at improving the living 
Sustainability Through Service Marketing-Below the line Bangladesh

conditions of the less privileged members of the society. SMC has gained international recognition due to its ability to positively influence the life of people in Bangladesh especially in the field of family planning and the use of contraceptives. Their promotion methods have also made it possible for people to conveniently access their goods more easily. Although their main aim is not to make profit, the company has been to experience great development in terms of profit making through the sale of their merchandises.

\section{Acknowledgements}

The people of Bangladesh of the majority of which disseminates living standard and keep their hopes high for a better world. The students of American International University- Bangladesh for their zest for learning and promise to serve their country better.

\section{REFERENCES}

[1]. Gerard, H. (2007). Social Marketing: Why Should the Devil Have All the Best Tunes? Butterworth-Heinemann. London: Oxford Publishers

[2]. McKenzie, M. (2003). Fostering Sustainable Behavior: An Introduction to Community-Based Social Marketing. Cambridge: Cambridge University Publishers.

[3]. Weinreich, N. (2010). Hands-On Social Marketing: A Step-by-Step Guide to Designing Change for Good(2nd Edition). Sage Publications.

[4]. Institute of Public Health and Nutrition (IPHN), Government of Bangladesh, "National Strategy for Anemia Prevention and Control in Bangladesh", 2007.

[5]. Harvey, D. (1999). "Let Every Child Be Wanted: How Social Marketing Is Revolutionizing Contraceptive Use Around the World. 